\title{
Development Strategy of Cultural Industry in Hebei Province Based on DEA Model
}

\author{
Wang Lixin \\ Sifang institute of Shijiazhuang railway university \\ Shijiazhuang, China \\ 58429562@qq.com \\ Gan Xiuna \\ Sifang institute of Shijiazhuang railway university \\ Shijiazhuang, China
}

\begin{abstract}
The cultural industry is the sunrise industry of the 21st century. Have the deep resources and the development of cultural industry in Hebei province background, how to turn a big province of cultural resources into a strong province cultural industry, is an important topic to research and solve in hebei province.

This paper expounds the present situation and characteristics of cultural industry development in Hebei province, through the establishment of the cultural industry in Hebei province efficiency evaluation index system, selection of cities in 2009-2013 cultural industry index data, using DEA model, efficiency of 11 cities of Hebei province cultural industry has carried on the empirical analysis, points out that the factors hindering the development of the cultural industry in Hebei province and the development of cultural industry strategic measures is given.
\end{abstract}

Keywords-DEA model; Hebei province; The cultural industry

Entering the new century, great changes have taken place in international economic form, cultural industry, environmental protection, biological technology and so on become the sunrise industry of 21 st century. Cultural industries involved in a wide range, and other areas of multi angle cross, its development is directly related to China's hard power and soft power upgrade.

Yanzhao earth, since ancient times more heroes, generous man, this is the spirit of the cultural development in Hebei. And Hebei province is one of the important birthplace of Chinese civilization. During the Warring States period, Hebei is the seat of YanZhao.Such as Handan, the capital of the ancient Zhao, has a reputation of the township of the idiom, Handan toddler, weiweijiuzhao, Fujing qingzui,Wanbiguizhao, Zhishangtanbing,many idioms born; and at Pingshan County, Hebei Sanji is the Warring States period in ruins, The temple of Zhengding is China's most ancient, one of the most complete preservation of the temple; new China goes from Xi Baipo, let people to pay tribute to leader style, get the power forward, but also to bring the rich red tourism resources.Hebei province is located in Beijing to trench, cultural heritage, has a wealth of cultural resources can be mining. Besides has the rich connotation of places of interest, the characteristics of Hebei folk art is the treasure of Chinese traditional folk art, like Gaocheng

\author{
Wang Suchao \\ Sifang institute of Shijiazhuang railway university \\ Shijiazhuang, China
}

lantern, wuqiao acrobatics, QuYang stones carving is famous in the world. Thus, the development of cultural industry in Hebei Province has a deep foundation and resources, how to turn a big province of cultural resources into a strong province cultural industry, is one of the important topics we need to study and solve.

\section{THE DEVELOPMENT OF CULTURAL INDUSTRY IN HEBEI PROVINCE}

\section{A. Red TaiHang mountains}

In recent years, Hebei Province Based on revolutionary tradition, patriotism education base construction of Taihang Mountains, in youth day, July 1 day, August 1 army day, eleven National Day holiday, memorial day to organize all kinds of thematic education activity, such as relive the party oath, etc. and free open war memorial. In recent years, the Taihang Mountains in the new period also launched to commemorate the war, the liberation war as the theme of cultural works of Art: film "who advocate ups and downs", red revolution TV drama "for the new China forward, TV documentary the 1949 Mao Zedong, symphony" Bai Po Symphony "important works. The launch of these works, strengthen the cultural education base of Xibaipo patriotism, which win support among the people. And at Xibaipo is the origin, radiation to the Taihang mountains. Created the Taihang Mountain cultural industry belt, gave birth to the red tourism, red film, red education and other red culture industry.

\section{B. The grand Great Wall}

The Great Wall over more than six thousand kilometers, even in outer space will also be able to see clearly. In the Chinese civilization for thousands of years of history, the Great Wall is not only a barrier against foreign invasion; more is regarded as the crystallization and symbol of the people's wisdom and hardworking. Within the territory of Hebei, the way to the Great Wall the longest, the most intact. In recent years, some of its background of the Great Wall in Hebei province cultural resources in mining. Such as projects of Hebei province was carried out on the Great Wall museum, has carried on the repair of the shanhaiguan section, and held the dragon-head-raising 
festival, shanhaiguan international ChangChengJie activities, have greatly enriched the Great Wall culture as an important symbol of our province. Thick, the Great Wall culture has a long history, with the development of tourism industry; the Great Wall will be of a major cultural tourism industry in our province.

\section{A righteous yanzhao}

In recent years, to create "honesty righteousness yanzhao culture" brand in Hebei province, the famous historical and cultural city in Hebei province has carried on the utilization and protection, protection of the ancient city of YanDou, guang fu ancient city ruins, the ancient city of Zhengding, GuZhongShan countries such as the historical and cultural sites. At the same time, use the media to vigorously carry forward the traditional culture, such as hebei farmers launched "drama stage", "the land of song" and other programs, for the hebei bangzi opera art forms coruscate gives new vitality.Hebei cangzhou construction the world acrobatics art center, let people around the world can enjoy the hebei proud, let the world amazing acrobatic art. Hebei yu county paper-cut in the UN list of intangible cultural heritage representative work ", by the world attention, etc., the yanzhao culture yanzhao earth are blooming flowers.

\section{Verve were reincarnated}

Hebei special geographical position, has long been a vault were reincarnated. Even the country road, maybe there is a story in it. Around Beijing and tianjin, has many traces, related to the royal as located Baoding zhili ZongDuShu, chengde summer resort, ZunHua Qingdongling, Yixian qing xiling, zhangbei county YuanZhongDou site, xuanhua drum tower, the boxers langfang triumph, such as cultural relics, manifests the national big communication integration the rich cultural color were reincarnated.In response to the integration of the beijing-tianjin-hebei region strategy, hebei for those routes, in Beijing, tianjin culture industry leading and radiation, some large, new type of cultural industry projects in hebei around of building, typical of shijiazhuang animation base, Baoding QuYang engraving art city, repair Chengde summer resort, etc. In addition, make beijing-tianjin-hebei bohai sea tourist area, borrows the beijing-tianjin-hebei regional integration accelerate the cultural industry in hebei construction is in a more broad space for development.

\section{E. Frolic in the bohai sea}

Emerging cities in hebei tangshan, bohai sea port city of qinhuangdao, it is an important engine of the rapid development in hebei. Tangshan as an important base of modern industry, has many footprints of modern industrial civilization, with a myriad of new China's first, first bucket mechanism of cement standard gauge, the first mechanical mine, the first railway, the first steam locomotive, etc. In tangshan earthIn recent years, Hebei Province of Tangshan modern industrial civilization were protected, "Nongchao Bohai culture brand building and on the basis of this, in the Bohai Sea area, the construction of the Kailuan mining industry in China the development of cultural tourism industry park, Beidaihe Creative Cultural Industry Park, the Grand Canal the chemical industrial park project; and launched the" Tangshan earthquake "outstanding film and television works, show the style and features of Hebei children, no doubt the cultural industry in Hebei Province to a powerful role in boosting.quake, tangshan people rebuild their home on the ruins, catching up spirit is admirable.

Relying on local resources characteristic, strong cultural industry development in hebei province, present a more distinct characteristics. According to statistics, in 2013, the added value of cultural industry in hebei province reached 95 billion yuan, $3.25 \%$ of GDP, the average annual growth rate over $30 \%, 20 \%$ higher than the entire province GDP annual increment. In 2014, the province cultural industry to realize the added value of about 112 billion, year-on-year growth of around 20\%, about $3.8 \%$ of GDP, is higher than $0.5 \%$ in 2013 . These statistics confirm the basis of the cultural industry has a certain strength, hebei province, showing a good development trend and the huge potential. But there is no denying the fact that all sorts of problems hindering the development of the cultural industry in hebei province and the worry still exists. The cultural industry in hebei province efficiency? Whether have reached the optimal? Is there any difference municipal cultural industry efficiency? This paper makes an empirical analysis using DEA model.

\section{THE DEA MODEL IS SET UP}

In 1978, operational research, A.C hames W.W.C ooper and "E.R hodes puts forward Data Envelopment Analysis method, DEA model for short. Data envelopment analysis is a non parametric statistical estimation method, which is based on the concept of relative efficiency. It can be used to evaluate the investment scale and technical efficiency of the same type.

Compared with other evaluation methods, the DEA method has a unique advantage. When using this method, do not need to determine the analysis of decision making units of production function; Each decision-making unit of input and output weights can be directly calculated by the model based on the optimality principle, to avoid the subjective evaluation index weight assignment; Can respectively based on the input Angle and output Angle analysis the effective decision units: in the case of the original output unchanged, how much less an input, or on the basis of the original input, an output how much increase.

The $C^{2} R$ model is the first DEA model, which is the ideal model for evaluating whether the decision making unit is the "technical efficiency" and "the best" in the assumption that the size of the yield is constant.In real life, however, because of all the factors, it is difficult to achieve efficiency under the assumption of constant return to scale.The actual formation of the effective production boundary is completed under the assumption of the size of the return of the scale. To this end,Chanes A.,Cooper W.,Golany B.,Seiford L.and Stutz J.and other scholars in 
1985 proposed an alternative $\mathrm{C}^{2} \mathrm{GS}^{2}$ model, which is $\mathrm{BC}^{2}$ model for evaluating the scale and the pure technology efficiency under the assumption of variable size returns. The relevant literature has been introduced to the $\mathrm{C}^{2} \mathrm{R}$ and $\mathrm{BC}^{2}$ model principle, this paper no longer, this paper mainly use the $\mathrm{BC}^{2}$ model.Three, index selection and operation results

\section{INDEX SELECTION AND OPERATION RESULTS}

First, consider the principles and requirements of the DEA model selection index, such as, the evaluation index is not easy to too much, or you will make the effectiveness of each decision-making unit coefficient tends to 1; There is relationship between input index and output index can but there should not be linear. Secondly, combing the current domestic scholars often used in the study of cultural industry efficiency index, combined with the data availability, this article selects 11 cities in hebei province, shijiazhuang, tangshan, qinhuangdao, handan, xingtai, baoding, zhangjiakou, chengde, cangzhou, langfang, hengshui, as the research sample, in cultural industry, cultural industry practitioners, gross assets as input indicators, with the added value of cultural industry, cultural industry output as output indicators, to quantify the efficiency of the 2013 cities in hebei province cultural industry empirical analysis.

TABLE I IN 2013 CITIES IN HEBEI PROVINCE CULTURAL INDUSTRY INPUT AND OUTPUT INDEX DATA

\begin{tabular}{|c|c|c|c|c|c|}
\hline $\begin{array}{c}\text { city } \\
\text { index }\end{array}$ & $\begin{array}{c}\text { Cultural } \\
\text { industry } \\
\text { output } \\
\text { (thousand } \\
\text { yuan) }\end{array}$ & $\begin{array}{c}\text { The added } \\
\text { value of } \\
\text { cultural } \\
\text { industry } \\
\text { (thousand } \\
\text { yuan) }\end{array}$ & $\begin{array}{l}\text { Practitioner } \\
\text { s (people) }\end{array}$ & $\begin{array}{l}\text { Number } \\
\text { of } \\
\text { institutio } \\
\text { ns (a)) }\end{array}$ & $\begin{array}{c}\text { Total assets } \\
\text { (thousand } \\
\text { yuan) }\end{array}$ \\
\hline Shijiazhuang & 529266 & 387055 & 10551 & 1549 & 1598556 \\
\hline Tangshan & 465199 & 352245 & 8414 & 1277 & 1280530 \\
\hline Qinhuangdao & 225433 & 145977 & 4549 & 636 & 667065 \\
\hline Handan & 326531 & 217286 & 7012 & 1108 & 777104 \\
\hline Xingtai & 206657 & 149670 & 5478 & 987 & 444673 \\
\hline Baoding & 411256 & 274711 & 9641 & 1800 & 1045156 \\
\hline Zhangjiakou & 787394 & 913117 & 6129 & 1218 & 1094367 \\
\hline Chengde & 465913 & 345741 & 5767 & 1054 & 626290 \\
\hline Cangzhou & 437348 & 314317 & 7031 & 1047 & 811591 \\
\hline Langfang & 423022 & 248522 & 5107 & 1107 & 859984 \\
\hline Hengshui & 141900 & 96078 & 3091 & 629 & 267621 \\
\hline
\end{tabular}

Data sources: cultural relics in hebei province statistics yearbook 2013

In the above data in table 1 , the number of culture industrial institutions for art industry, libraries, public cultural services, art education, literature and art research, cultural industry, cultural market management mechanism for the number of total and other institutions. According to the nature of the unit includes institutions and enterprises.

The number of employees in the culture industry covers the arts, libraries, mass culture, art education, literature and art research, cultural property, cultural marketing and other aspects of the employees.
Assets is based on the cultural relics in hebei province in 2013 statistical yearbook of each region enterprises assets total, regional administration, institution assets calculated the sum of the total.

The added value of cultural industry reflects the cultural industry in the process of production and service agencies to create new value and the transfer of fixed assets value, reflects the period of the final results of the production and business operation activities, the parameter values for the sum of worker pay, production tax net, depreciation of fixed assets and operating surplus.

Cultural industry output is the art industry, library, mass culture, art education, cultural market management institutions, literature and art research, and other aspects of the total output of property.

In this paper, through the establishment of various cities in hebei province cultural industry efficiency evaluation index system, using DEA method B2R model, and use of DEAP2.1 software, the data in table 1 input, run part of the output results are shown in table 2 .

TABLE II MODEL EVALUATION RESULTS OF THE DECISION MAKING UNITS 1

\begin{tabular}{|c|l|l|l|l|}
\hline $\begin{array}{c}\text { city } \\
\text { Operating results }\end{array}$ & $\begin{array}{c}\text { crste } \\
\text { Comprehensive } \\
\text { technical efficiency) }\end{array}$ & $\begin{array}{c}\text { vrste } \\
\text { (Pure technical } \\
\text { efficiency) }\end{array}$ & $\begin{array}{c}\text { scale } \\
\text { (scale efficiency) }\end{array}$ & scale return \\
\hline Shijiazhuang & 0.529 & 0.672 & 0.786 & drs \\
\hline Tangshan & 0.564 & 0.591 & 0.954 & drs \\
\hline Qinhuangdao & 0.548 & 1.000 & 0.548 & irs \\
\hline Handan & 0.573 & 0.573 & 1.000 & - \\
\hline Xingtai & 0.625 & 0.685 & 0.912 & irs \\
\hline Baoding & 0.529 & 0.546 & 0.969 & drs \\
\hline Zhangjiakou & 1.000 & 1.000 & 1.000 & - \\
\hline Chengde & 1.000 & 1.000 & 1.000 & - \\
\hline Cangzhou & 0.741 & 0.761 & 0.974 & irs \\
\hline Langfang & 0.681 & 0.742 & 0.919 & irs \\
\hline Hengshui & 0.713 & 1.000 & 0.713 & irs \\
\hline Accor & & \\
\hline
\end{tabular}

According to DEA method, the technical efficiency means that under the precondition of existing resources, decision making units to achieve the maximum output, or on a given level of output, and resources to achieve the minimum. Analysis in table 2, from the overall, 11 cities in hebei province in 2013 cultural industry comprehensive technical efficiency in the medium level, 11 cities the index's average of 0.684 , only two cities achieved effective, accounting for $18.18 \%$ of the whole city. A total of six cities should acquire basic between 0.5 to 0.6 , show the allocation of resources capacity in hebei province culture industry resources and efficient use of resources is not good enough; Pure technical efficiency has four cities are effective, the other is between 0.54 to 0.76 .

If the current multiples of various resources to increase, resulting in the corresponding output also increased multiples of the same, you can say the decision making units in the stage of constant return to 
scale, the scale of effective, otherwise known as the increasing return to scale, small production scale or decreasing return to scale, production scale is larger. Analysis concluded in table 2, 11 cities in hebei province cultural industry scale efficiency is higher, in addition to qinhuangdao 0.548 , shijiazhuang 0.786 , other all above the 0.9 level.

So, on the whole, 2013 cities in hebei province cultural industry of the input and output is effective. The other, from the point of scale reward, is at a stage of scale pay the same number of cities have 3, handan, zhangjiakou, chengde, accounted for 27\%; In the stage of scale increasing return city has five, respectively is qinhuangdao, xingtai, langfang, cangzhou, hengshui, accounted for $45 \%$, illustrate the above eight cities culture industry is in the intermediate stage of development.

To reflect the dynamics and continuity of research, make the results more convincing, still above selected input and output indicators, 11 cities will examine the input and output data from 2009 to 2013, respectively, and the arithmetic mean, in order to get the average as cities new input and output (as shown in table 3), using DEAP software can get each city from 2009 to 2013 the average technical efficiency, pure technical efficiency and scale efficiency (as shown in table 4).

TABLE III MUNICIPAL CULTURAL INDUSTRY IN HEBEI PROVINCE IN 20092013 AVERAGE INPUT AND OUTPUT INDEX

\begin{tabular}{|c|c|c|c|c|c|}
\hline \multicolumn{1}{|c|}{ city } & $\begin{array}{c}\text { Cultural } \\
\text { industry } \\
\text { output } \\
\text { (thousand } \\
\text { yuan) }\end{array}$ & $\begin{array}{c}\text { The added } \\
\text { value of } \\
\text { cultural } \\
\text { industry } \\
\text { (thousand } \\
\text { yuan) }\end{array}$ & $\begin{array}{l}\text { Practitione } \\
\text { rs (people) }\end{array}$ & $\begin{array}{l}\text { Number of } \\
\text { institutions } \\
\text { (a)) }\end{array}$ & $\begin{array}{c}\text { Total assets } \\
\text { (thousand } \\
\text { yuan) }\end{array}$ \\
\hline Shijiazhuang & 621538 & 449166 & 12399 & 1910 & 1400302 \\
\hline Tangshan & 439074 & 390262 & 8336 & 1323 & 953657 \\
\hline Qinhuangdao & 243655 & 161743 & 4074 & 650 & 563687 \\
\hline Handan & 252560 & 192808 & 6357 & 1131 & 564974 \\
\hline Xingtai & 239937 & 199841 & 5547 & 1062 & 422188 \\
\hline Baoding & 421681 & 308033 & 10100 & 1844 & 1027078 \\
\hline Zhangjiakou & 485807 & 494468 & 5926 & 1134 & 1052944 \\
\hline Chengde & 491607 & 391085 & 6286 & 1168 & 645605 \\
\hline Cangzhou & 344671 & 253874 & 6314 & 1001 & 550485 \\
\hline Langfang & 321563 & 222143 & 5483 & 1149 & 860641 \\
\hline Hengshui & 82202 & 63244 & 2448 & 511 & 159092 \\
\hline
\end{tabular}

Data sources: according to the cultural relics in hebei province in 2009-2013 statistical yearbook of each index data calculation and arrangement
TABLE IV MODEL EVALUATION RESULTS OF THE DECISION MAKING UNITS 2

\begin{tabular}{|c|l|l|l|l|}
\hline $\begin{array}{c}\text { crste } \\
\text { city } \\
\text { index }\end{array}$ & $\begin{array}{c}\text { (comprehensive } \\
\text { technical efficiency) }\end{array}$ & $\begin{array}{c}\text { vrste } \\
\text { (Pure technical } \\
\text { efficiency) }\end{array}$ & $\begin{array}{c}\text { scale } \\
\text { (Scale efficiency) }\end{array}$ & Scale return \\
\hline Shijiazhuang & 0.767 & 1.000 & 0.767 & drs \\
\hline Tangshan & 0.782 & 0.886 & 0.902 & drs \\
\hline Qinhuangdao & 0.878 & 1.000 & 0.878 & irs \\
\hline Handan & 0.587 & 0.596 & 0.985 & irs \\
\hline Xingtai & 0.781 & 0.831 & 0.941 & irs \\
\hline Baoding & 0.543 & 0.757 & 0.718 & drs \\
\hline Zhangjiakou & 1.000 & 1.000 & 1.000 & - \\
\hline Chengde & 1.000 & 1.000 & 1.000 & - \\
\hline Cangzhou & 0.822 & 0.873 & 0.941 & irs \\
\hline Langfang & 0.725 & 0.750 & 0.966 & irs \\
\hline Hengshui & 0.679 & 1.000 & 0.679 & irs \\
\hline The & & & \\
\hline
\end{tabular}

The conclusion analysis table 4 and table 2 are very similar. 11 cities in hebei province in 2009-2013 cultural industry comprehensive technical efficiency in the medium level slightly, 11 cities the index's average of 0.779 , is still of zhangjiakou and chengde two cities of only achieved the effective; Pure technical efficiency has five cities is effective. 11 cities in hebei province in 2009 2013, the cultural industry scale efficiency is higher, in addition to hengshui 0.679 , baoding is 0.718 , shijiazhuang 0.767 outside, other all at about 0.9 , and most of the above the 0.9 level. Therefore, as a whole, each city cultural industry of the input and output is effective.

From the scale of remuneration, the number of cities in the scale of constant returns to the same stage and the stage of decreasing returns to scale are 2 and 3 , and there are 6 cities in the stage of increasing returns to scale.

Combined with the technical efficiency and scale efficiency, scale efficiency is higher for most cities in hebei province cultural industry and technical efficiency is insufficient, therefore, maintain the current scale of production, improve the production efficiency is the key in the future development.

\section{INFLUENCE FACTORS HINDERING THE DEVELOPMENT OF THE CULTURAL INDUSTRY IN HEBEI PROVINCE}

The cultural industry in hebei province technical efficiency is not high, showing the sank input and output is insufficient, and there are several key problems in the development of cultural industry in Hebei Province:

\section{A. It is the cultural industry in hebei province market main body does not reach the designated position.}

For now, the competent department of culture system is often established authority or authority institution, rather than the business itself, there exists a rigid system, management confusion, strong planning, lower efficiency.

\section{B. The diversified investment subject does not reach the designated position.}

To development of cultural industry, it needs large investment, the current situation in hebei province, the investment mainly comes from funding and opportunistic 
personal investment, and didn't have a complete system to protect the funds in place.

C. Policy measures are not in place, the local government planning their respective area of the cultural industry, ignore the regional differences and market demand, expand blindly invest construction, repeat construction is more, there is no unified planning and requirements, eventually lead to the early stage of the culture industry investment is huge, the late is not ideal.

\section{THE CULTURAL INDUSTRY IN HEBEI PROVINCE DEVELOPMENT STRATEGIC MEASURE}

Concentrating on industry and investment subject, improve the supporting policies and measures, will help to develop the cultural industry in hebei province. Fundamentally, the cultural industry, is developed on the basis of culture, and must have the economy. So, to the development of cultural industry, must be based on two points: the local and the economy. To change the big province of cultural industry in hebei province for a powerful province of cultural industry. Development of cultural industry in hebei province can adopt the following strategy:

\section{A. Balanced regional development}

Cities in hebei province cultural industry efficiency gap can lead to lower overall efficiency. Therefore, we should pay attention to implement the strategy of regional balanced development, narrowing gap between cities in hebei province cultural industry development. According to the characteristics of each city cultural industry development to formulate the corresponding development countermeasure, and enhance its cultural industry efficiency. Shijiazhuang for example, is the largest regions in the development of cultural industry in hebei province, cultural industry professionals, has a high added value of cultural industry.

But the cultural industry in shijiazhuang, baoding, tangshan are diminishing returns of scale stage, output growth is lower than the speed of growth, and is not appropriate to expand, in the future should focus on to develop in the direction of "doing fine, fine", reduce unnecessary spending, avoid the waste of resources. Handan, hengshui culture industry development is relatively slow, these cities can be moderately expand the scale of the cultural industry, further development and utilization of its own cultural resources.

\section{B. Based on characteristic resource advantage, promote cultural resources benefit maximization}

Should be based on the advantage of the rich cultural resources in hebei province, through excavation, protection and utilization, inheritance, resources advantages into industrial advantages and cultural advantages to develop advantages. Around at the same time, must dig deeper into local characteristic cultural resources, with historical and cultural city, cultural advanced county, township of the folk arts and crafts processing production base as the carrier, for regional cultural industry positioning, with characteristic elements, brand building, formed the scale, do long do best cultural industry chain length.

\section{Pay attention to local talent and high and new technical talents training}

On the one hand, on the talent training and the introduction in hebei province to form conforms to the local cultural characteristics and requirements of the training and introduction mechanism. In other words, it is to pay attention to the cultivation of local talents. On the other hand, using the advantages of higher education resources to actively carry out the training of high-end cultural industry talents, through the scientific development of training objectives, innovative professional curriculum, strengthen the construction of teachers, build teaching practice platform, and gradually form a reasonable and effective training mode, strengthen the cultivation of innovative and high-tech talents.

\section{Increase investment in science and technology}

To achieve the rapid development of the cultural industry, we must rely on the network technology, electronic printing technology, animation manufacturing and other high-tech. The development of cultural industries, can not blindly expand the number of inputs, but to focus on quality. Should continue to increase scientific and technological input, and constantly promote the cultural field of scientific and technological innovation, the use of high-tech means to upgrade the traditional culture industry, so as to improve economic efficiency, in the limited resources to create the largest output.

\section{ACKNOWLEDGEMENT}

This paper is the 2015 annual social science research and development of Hebei Province, based on the SWOT analysis and DEA model of Hebei province county characteristics and cultural industry development strategy research" part of the results (subject to the approval number: 201501938)"

\section{REFERENCES}

[1] liu Li-juan. County cultural industry development and urban and rural spatial layout research - YueChi county, sichuan province, for example [D]. Chongqing normal university, 2011.04

[2] Wang Jia. Regional culture and regional features of cultural industry development [J]. China's culture industry, 2013.01

[3] liu Zun-feng, Wang Xiao-ci. The county territory characteristic culture industry development in hebei province to explore [J] Ecological economy, 2013.02 